Mercè RodOREDA

Sa Pratza de su Diamante

Trad. i notes de Giagu Ledda

Nuoro: Editorial Papiros, 2008

Als cinquanta anys de la seva publicació, La Plaça del Diamant de Mercè Rodoreda s'ha traduït a 33 llengües, entre les quals recordem el búlgar, l'hebreu o el basc. Al llarg llistat de traduccions d'aquesta obra fonamental de la literatura catalana contemporània, se n'ha afegit una altra de nova, Sa Pratza de su Diamante, transposició de la novel.la a la llengua sarda.

A partir dels anys 80 del segle passat, va començar a fer-se palès a Sardenya una sensibilització lingüística cada vegada més forta, i un desig de donar a la llengua sarda una projecció nacional i internacional que dugués aquest idioma al mateix prestigi social posseït per altres llengües històriques. La Legge Regionale de "Promoció i valorització de la cultura i de la llengua sarda» (1997) va contribuir, sense lloc a dubte, a aquest procés de sensibilització, així com tot el llarg procés - encara en curs - de creació d'una norma lingüística que permetés als parlants del sard poder donar una major difusió escrita a aquesta llengua que es parla cada vegada menys (per a aprofundir més en el tema $c f r$. Roberto BOLOGNESI, «Il sardo tra isolamenteo e contatto: Una rianalisi di alcuni stereotipi», Ianua, n. 2, 2001, p. 1-47; Roberto BOLOGNESI, Una normalizzazione democratica del sardo. Norme per una convivenza pacifica delle varietà del sardo, Cagliari: Condaghes, 2002; Mario ARgIOLAS i Roberto SERRA (eds.), Limba lingua language. Lingue locali, standardizzazione e identità in Sardegna nell'era della globalizzazione, Cagliari: CUEC, 2001; Ines LOI CORVETTO, L’italiano regionale di Sardegna, Bologna: Zanichelli, 1983; entre d'altres). Els canvis que Sardenya ha experimentat amb la introducció de les noves tecnologies o l'augment significatiu de mitjans de comunicació - majoritàriament en italià- ha empitjorat l'ús social del sard en els contextos de relació en la comunitat de parlants. En conseqüència, si no s'adopten mesures per assegurar-ne l'ús social es degradarà formalment $i$ es convertirà en un instrument de comunicació residual (cfr. Filippo MELIS, «La llengua sarda: descripció tipològica i sociolingüística», article disponible a la pàgina web www.udg.edu/odelleum, 2008). Segons el que ens va dir el traductor, Giagu Ledda, el que preval en aquest procés de normalització lingüística, és que «es comenci a escriure en sard», fet que sent com una responsabilitat personal i social. Giagu Ledda ens va explicar que l'elecció d'aquesta novel.la es devia a «'amore pro su sardu e pro su catalanu» (a l'amor que sent per al sard i per al català). La lectura d'aquesta obra catalana va despertar en el traductor un sens fi d'emocions - a causa de les nombroses analogies existents entre les dues llengües - $\mathrm{i}$ la necessitat natural de bolcar la història de Colometa a sa limba, a la llengua sarda. I realment ho va aconseguir. Possiblement es degui a la història comuna posseïda per les dues cultures $i$, per tant, llengües; la gran influència lingüística que va tenir el català sobre el sard es palesa en moltes de las paraules que formen aquesta novel.la: "Tenia una cara in dae in antis meu» (p. 6), "Fia torrada a domo cun duas ampullas» (p. 31), «Sa faina de Quimet fiant minimende» (p. 47), "ca cando ischiat chi Quimet fiat in domo non s'atriviat a intrare» (p. 83), etc.

Amb la traducció de la novel.la rodorediana, Giagu Ledda intenta obrir una porta a la llengua sarda per a que pugui sortir de l'estatus de «llengua de l'oralitat». Tot i així, aquest tret característic del sard possiblement hagi pogut afavorir la traducció de l'obra, ja que es tracta d'una 
novel.la en què «la supressió del narrador permet [...] una forta impressió de mimesi i, per tant, un efecte dens de la vida, cosa que s'accentua pel tipus d'escriptura [...]: l'escriptura parlada» (cfr. Carme ARNAU, Introducció a la narrativa de Mercè Rodoreda. El mite de la infantesa, Barcelona: Edicions 62, 1979, p. 118). Giagu Ledda aconsegueix transmetre perfectament, en aquesta traducció, les vivències i els sentiments de Natàlia/Colometa:

Mi so posta torra ogros a sa ghenna e a punta
de gurteddu apo iscritu, a literas mannas
[...] Colometa: [...] e nche fia cròmpida a
sa pratza de su Diamante: [...] e, tapen-
de.mi sa cara cun sos bratzos pro mi repa-
rare no isco dae ite, apo fatu unu tzichirriu
indimoniadu. Unu tzichirriu chi de segu-
ru giughia in corpus dae annos e cun cussu
tzichirriu, gasi mannu chi agiumai no mi
passaiat in gula, mi nche fiat essida dae buca
unu pagu de cosa, [...] e cussu pagu de cosa
chi aiat bividu pro tantu tempus inserrada
in intro, fiat sa gioventude mea chi si nche
fuiat cun unu tzichirriu chi no ischia bene ite fiat...» (p. 125) («I em vaig girar d'esquena a la porta i amb la punta del ganivet $\mathrm{i}$ amb lletres de diari vaig escriure Colometa, [...] i vaig ficar-me a la plaça del Diamant: [...] i amb els braços davant de la cara per salvar-me de no sabia què, vaig fer un crit d'infern. Un crit que devia fer molts anys que duia a dintre $\mathrm{i}$ amb aquell crit, tan ample que li havia costat de passar-me pel coll, em va sortir de la boca una mica de cosa de no-res, [...] i aquella mica de cosa de no-res que havia viscut tant de temps tancada a dintre, era la meva joventut que fugia amb un crit que no sabia ben bé què era....", Mercé RodoredA, La plaça del Diamant, Barcelona: Editorial Planeta, p. 190-191).

Creiem que la discussió ontològica entorn de les traduccions s'anul.la una vegada llegida Sa Pratza de su Diamante, ja que el traductor aconsegueix plasmar aquells trets i peculiaritats que comparteixen la llengua i la cultura sarda i catalana.

Daniela Ibba

\section{Tito SAFFIOTI}

\section{Gli occhi della follia. Giullari e buffoni di corte nella storia e nell'arte} Milano: Book Time, 2009

L'ofici de joglar ha estat un dels més denigrats en la història d'Occident, essent com és un dels mesters més importants de la societat. Important perquè no només va ser durant segles el principal agent del divertiment, sinó també l'únic dipositari de l'herència teatral antiga que sobreviu al genocidi cultural perpetrat per l'Església medieval i pels poders que la sostenen. La joglaria salva el teatre de l'acarnissada destrucció i fanàtica persecució a què el va sotmetre el cristianisme. Durant gairebé un mil.lenni són els joglars qui mantenen viu el testimoni de la representació escènica, de les tècniques interpretatives, del conjunt de procediments actorals i narra- tius que constituïen la columna vertebral de l'imaginari de la població, i que acabaran essent vampiritzats pels frares predicadors enlluernats per l'eficàcia comunicativa dels joglars. El seu art alegrava, entretenia, informava i, sobretot, mantenia viu l'esperit crític de la gent envers els poders establerts i els sistemes dominants. Amb humor, amb ironia, amb burla, el joglar sembrava la llavor de la contestació i la resistència davant l'autoritat incontestable i sempre abusiva. És per això que el seu ofici va ser perseguit i malfamat, tot i que també finalment protegit per aquells poderosos que en el fons s'avorrien sense la sal i el pebre joglaresc, fins al punt que la 